\title{
Growth and characterization of some novel crystals for nonlinear optical applications
}

\author{
H L BHAT \\ Department of Physics, Indian Institute of Science, Bangalore 560012, India
}

\begin{abstract}
The advent of high intensity lasers coupled with the recent advances in crystal technology has led to rapid progress in the field of nonlinear optics. This article traces the history of materials development that has taken place over the past forty odd years and dwells on the current status in this important area. The materials aspect is discussed under three classes viz. inorganic, organic and semiorganic crystals. In the end, some of the crystal growth work that has been carried out in author's laboratory is presented.
\end{abstract}

Keywords. Nonlinear optics; polarizability; second harmonic generation; semiorganics; crystal growth.

\section{Introduction}

In its long history, optics, until the advent of lasers, remained linear. The tenets of linear optics are based on the assumption, valid under the first approximation, which provides the linear dependence of polarization wave generated in the medium on the interacting electromagnetic field:

$$
P=\varepsilon_{0} \chi E \text {. }
$$

As a result of the oscillating nature of the field associated with the radiation, the induced dipoles will oscillate and thus act as sources of radiation. When the radiation field is large, the induced polarization would become nonlinear and its dependence on the radiation field is represented by

$$
P=\varepsilon_{0}\left(\chi^{(1)} E+\chi^{(2)} E^{2}+\chi^{(3)} E^{3}+\cdots\right)
$$

An immediate consequence of this is the generation of fields at frequencies different from those of the incident radiation. For example, if the incident radiation is represented by

$$
E=E_{0} \cos \omega t
$$

then the quadratic term in $E$ of (2) yields a component at twice the fundamental frequency, i.e.

$$
E^{2}=E_{0}^{2} \cos ^{2} \omega t=\frac{1}{2} E_{0}^{2}(1+\cos (2 \omega t)) .
$$

Similarly substituting (3) into (2) gives for the cubic term a component at three times the fundamental frequency. The two examples cited above are referred to as optical second and third harmonic generations respectively. In addition, there are other exotic effects such as parametric oscillation, rectification, optical phase conjugation, etc which manifest at high optical fields. However, frequency conversion is the most 
studied nonlinear optical (NLO) process and is particularly important in device applications.

\section{Materials perspectives}

Ever since the first demonstration of second harmonic generation (SHG) in quartz (Franken et al 1961), progress in nonlinear optics has always been dictated by the availability of better and newer materials. The conversion efficiency of the second harmonic generation process is given by (Yariv 1985)

$$
\eta_{\mathrm{SHG}}=\frac{P_{2 \omega}}{P_{\omega}}=2\left(\frac{\mu}{\varepsilon_{0}}\right)^{3 / 2} \frac{\omega^{2} d^{2} l^{2}}{n^{3}} \frac{\sin ^{2}(\Delta k l / 2)}{(\Delta k l / 2)^{2}} \frac{P_{\omega}}{A} .
$$

Here $d$ is the effective nonlinear optical coefficient and $k$ the wave vector. For a given material and for a given frequency $(\omega)$ the conversion efficiency is dependent on the square of the interaction length $l$, hence it is imperative that large crystals are needed. As a result of the interference from the input fundamental polarization wave and the driven harmonic polarization wave, the maximum usable length of the crystal is limited to a few microns. However, this problem could be circumvented by decreasing $\Delta k$ to zero, technically known as phase matching. The quotient $d^{2} / n^{3}$ is called the figure of merit for SHG. This is a material-limited parameter, often meriting the first consideration, in the search for newer materials. In a chosen material and a selected interaction geometry, conversion efficiency can be further enhanced by increasing the power density $\left(P_{\omega} / A\right)$ of the input beam. This can be physically achieved by focusing the beam into the crystal, increasing the power densities to the tolerance limit, called the damage threshold.

The above discussion on the parameters influencing the conversion efficiency is for plane wave approximation of the incident beam and is valid essentially when the crystal acceptance widths are much broader than those of the laser beam. A more detailed consideration of the beam and crystal parameters gives the phase mismatching parameter $\Delta S$ as (Lin 1988),

$$
\Delta S=K_{1}(\Delta \theta . L)+K_{2}(\Delta T . L)+K_{3}(\Delta \hat{\lambda} . L)
$$

where $(\Delta \theta . L),(\Delta T . L)$ and $(\Delta \lambda . L)$ are defined as the angular, temperature and spectral bandwidths respectively, of the crystal. Hence it is essential that the temperature and spectral bandwidths are also considered while opting for a crystal for an NLO device.

In addition to the above parameters, a few other physical properties of the crystals need to be considered. For example, the chosen material should have large transparency window, high melting point, mechanical stability and chemical inertness. There are very few materials which satisfy most of these requirements. Hence the search for new materials seems to be unending. Though other forms of materials, like thin films, polymers, etc. are also currently being explored, the discussion herein is limited to single crystals. 


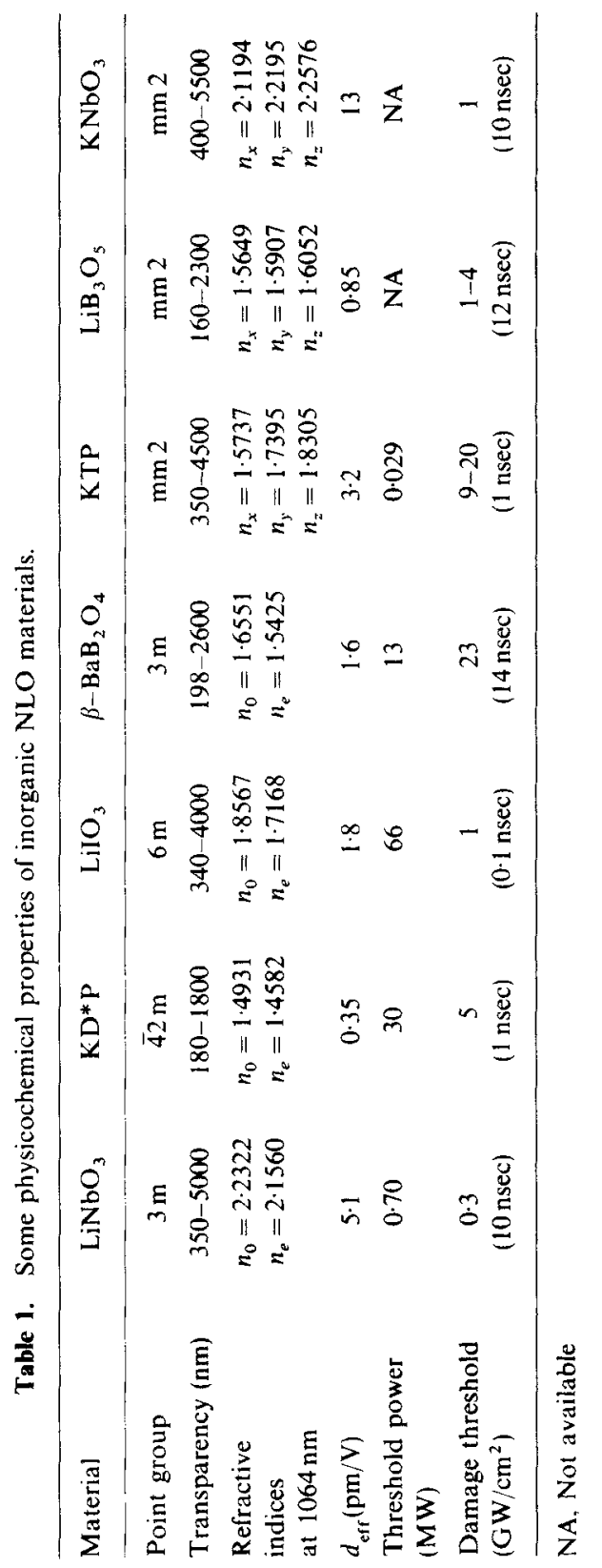




\subsection{Inorganic crystals}

In the initial stages, the materials explored for nonlinear optical applications had always been inorganic. Many inorganic crystals are well studied in terms of their physical properties. Since these materials are mostly ionic bonded, it is always easier to synthesize inorganic materials. Often these have high melting points and high degree of chemical inertness. High-temperature oxide materials are well studied for diverse applications like piezoelectricity, ferroelectricity, pyroelectricity and electrooptics. Hence when the search for new materials began in NLO, scientists often trusted their intuition, screened the known materials, and were fairly successful. Some of the most useful crystals discovered are $\mathrm{LiNbO}_{3}, \mathrm{KNbO}_{3}$, potassium dihydrogen phosphate (KDP) and its analogues, potassium titanyl phosphate and its analogues, beta barium borate, etc. Indeed most of the commercial frequency doublers used presently are all made of these inorganic materials. Table 1 summarizes the present status of these materials, comparing all the device-related parameters. However, as early as 1969, Bergman et al (1969) indicated that inorganic materials have only $\approx 20 \%$ probability of acentricity. Hence in the search for newer materials with higher nonlinearity, inorganics stand a poor chance and the advances have been limited in the past two decades.

\subsection{Organic materials}

Organic compounds are often formed by weak van der Waals and hydrogen bonds and hence possess high degree of delocalization. Thus they are expected to be optically more nonlinear than inorganic compounds. Some of the advantages of organic materials include ease of varied synthesis, scope for altering the properties by functional substitutions, inherently high nonlinearity, high damage resistance, etc. The prototype organic NLO material contains one or more delocalized bonds, typically a ring structure like benzene. When substituted with donor and acceptor

Table 2. Some physicochemical properties of organic NLO materials.

\begin{tabular}{|c|c|c|c|c|c|c|}
\hline Material & MNA & POM & DAN & MMONS & MBANP & MAP \\
\hline Point group & $\mathrm{mm} 2$ & 222 & 2 & $\mathrm{~mm} 2$ & 2 & 2 \\
\hline Melting point $\left({ }^{\circ} \mathrm{C}\right)$ & 114 & 136 & 166 & NA & 84 & $80 \cdot 9$ \\
\hline Transparency (nm) & $480-2000$ & $500-1700$ & $485-2700$ & $510-2100$ & NA & $500-2500$ \\
\hline $\begin{array}{l}\text { Refractive } \\
\text { indices at } 1064 \mathrm{~nm}\end{array}$ & $\begin{array}{c}n_{x}=1.800 \\
n_{y}=1.600 \\
n_{z}=?\end{array}$ & $\begin{array}{l}1.663 \\
1.829 \\
1.625\end{array}$ & $\begin{array}{l}1.517 \\
1.636 \\
1.843\end{array}$ & $\begin{array}{l}1.530 \\
1.630 \\
1.961\end{array}$ & $\begin{array}{l}1.650 \\
1.714 \\
1.688\end{array}$ & $\begin{array}{l}1 \cdot 507 \\
1 \cdot 59 \\
1 \cdot 843\end{array}$ \\
\hline $\begin{array}{l}\text { Nonlinear } \\
\text { coefficient } \\
\left(\times 10^{-9} \text { esu }\right)\end{array}$ & $\begin{array}{l}d_{11}=60 \\
d_{12}=90\end{array}$ & $\begin{array}{l}d_{14}=23 \\
d_{25}=23 \\
d_{36}=23\end{array}$ & $\begin{array}{l}d_{22}=12 \cdot 4 \\
d_{23}=119\end{array}$ & $\begin{array}{l}d_{24}=55 \\
d_{32}=41 \\
d_{33}=184\end{array}$ & $d_{22}=8 \cdot 3$ & $\begin{array}{l}d_{21}=40 \\
d_{22}=44 \\
d_{23}=8.8\end{array}$ \\
\hline $\begin{array}{l}\text { Damage threshold } \\
\left(\mathrm{GW} / \mathrm{cm}^{2}\right)\end{array}$ & $\begin{array}{c}0.2 \\
(20 \mathrm{nsec})\end{array}$ & $\begin{array}{c}2 \\
(0 \cdot 02 \mathrm{n} \mathrm{sec})\end{array}$ & $\begin{array}{c}5 \\
(10 n \mathrm{sec})\end{array}$ & $\mathrm{NA}$ & $\begin{array}{c}1 \\
\left(12 \mathrm{nsec}^{2}\right)\end{array}$ & $\begin{array}{c}3 \\
(10 n \sec )\end{array}$ \\
\hline
\end{tabular}

MNA: 2-methyl-4-nitroaniline; POM: 3-methyl-4-nitropyridine-1-oxide; DAN: 4-(N,N-dimethylamino)3-acetamido nitrobenzene; MMONS: 3-methyl-4-methoxy-4'-nitrostilbine; MBANP: 2-( $\alpha$-methylbenzylamino)-5-nitropyridine; MAP: methyl-(2,4-dinitrophenyl)-amino-2-propanate. 


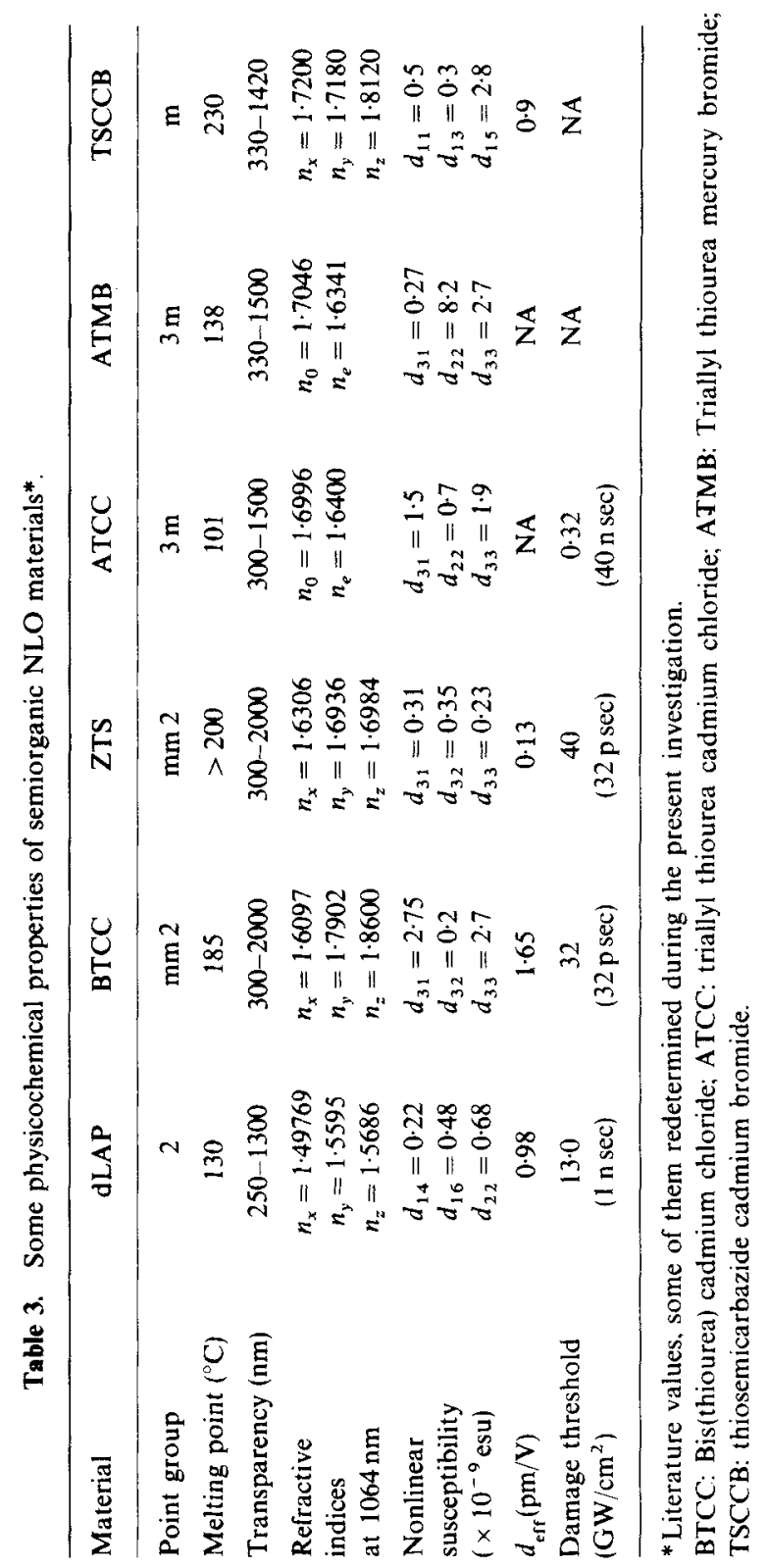


at the para position, (e.g. p-nitroaniline) they have large induced dipole moments under the influence of electromagnetic fields. However, such structures, when packed as crystals, tend to be mostly centrosymmetric, thus leading to vanishing dipole moment. A suitable addition at another site, as in the case of 3-methyl 4-nitroaniline, can ensure a macroscopically non-vanishing dipole moment for the donor-acceptorsubstituted systems. The above example typifies the strategy of molecular engineering towards achieving efficient nonlinear materials (Chemla and Zyss 1987). Table 2 gives the list of well-developed organic NLO materials and their physical properties. However, there has been little progress in fabricating devices out of these molecular crystals. These crystals have several unfavourable physical parameters. Large dipole moment which leads to the large $\chi^{(2)}$ is also responsible for increased absorption at higher frequencies. Hence most of these molecular materials have poor transparency and small transparency windows. Consequently, the generated harmonic wave gets absorbed in the crystal, leading to poor efficiency. Also, organic NLO materials are inherently poor in mechanical hardness, and have low melting points and poor chemical inertness. Owing to the high polar nature of the molecules they often tend to crystallize as long needles or thin platelets.

\subsection{Semiorganic materials}

The inherent limitation on the maximum attainable nonlinearity in inorganic materials and the moderate success in growing device-grade organic single crystals have made scientists adopt newer strategies. The obvious one was to develop hybrid inorganic-organic materials with little trade-off in their respective advantages. This new class of materials has come to be known as the semiorganics (Newman et al 1990). One approach to high-efficiency, optical-quality organic-based NLO materials in this class is to form compounds in which a polarizable organic molecule is stoichiometrically bonded to an inorganic host. A typical case is the formation of inorganic salts of chiral organic molecules (classified as type I). L-Arginine phosphate monohydrate (LAP) is an example of this class. The choice of organic molecules to form salts are plenty. For example tartrates, oxalates and amino acid salts are predominantly NLO-active.

An alternate approach is to form metal coordination complexes of organic materials (type II). The choices for ligands in type II are unlimited. In fact, the organic part need not be noncentrosymmetric. This is typified by the example of thiourea, which forms excellent complexes with $\mathrm{Zn}, \mathrm{Cd}$ and $\mathrm{Hg}$. Thiourea is more polarizable than urea because of the presence of large sulphur atoms and the hydrogen bonds in $\mathrm{NH}_{2}$ ensure the lack of centre of inversion in many thiourea complexes. The other popular choices for ligands in type II are allylthiourea, guanidium and dithiocarbamate.

An added advantage of this class of materials is that they have moderate nonresonant $\chi^{(3)}$ which can be resonantly enhanced by doping with metals that can absorb in the operable wavelength. For example, zinc tris (thiourea) sulphate (ZTS) has a $\chi^{(3)}$ value 0.1 times that of $\mathrm{CS}_{2}$ which can be enhanced to 1.5 times $\mathrm{CS}_{2}$ by doping it with Co at 10 ppm (Newman et al 1990). Table 3 gives a list of some of the semiorganic compounds and their physical properties. 


\section{Crystal growth}

We have been working on the growth and characterization of a number of nonlinear optical materials over the past few years. Notable amongst them are the KDP family of crystals, LAP and its deuterated analogue dLAP, ZTS, BTCC, 3-methoxy-4hydroxybenzaldehyde (MHBA) (all grown from solution), $\mathrm{LiNbO}_{3}$ and potassium titanyl phosphate (KTP). For want of space detailed account of the investigations carried out on them will not be given here. Below we describe only the growth aspects of some of these crystals.

\subsection{Lithium niobate}

Lithium niobate $\left(\mathrm{LiNbO}_{3}\right)$ continues to be one of the technologically important materials because of its diverse applications (INSPEC 1989; Prokhorov and Kuzminov 1990). The increasing applications of $\mathrm{LiNbO}_{3}$ crystals with more and more stringent specifications have required continued studies on the growth and characterization of this crystal. High-quality $\mathrm{LiNbO}_{3}$ crystals are grown by the Czochralski technique.

In our case $\mathrm{LiNbO}_{3}$ was synthesized from $\mathrm{Li}_{2} \mathrm{CO}_{3}$ and $\mathrm{Nb}_{2} \mathrm{O}_{5}$. The congruent composition ( $\mathrm{Li}_{2} \mathrm{CO}_{3} 48.45$ mole $\%$ ) was prepared through solid-state reaction in a platinum crucible. Autox oxide puller, custom built to grow oxide crystal boules of $25 \mathrm{~mm}$ diameter by Cambridge Instruments, England, was employed in the growth experiments. Seed crystals were prepared from $c$-axis-grown $\mathrm{LiNbO}_{3}$ boule. The charge was contained in a platinum crucible of dimensions $50 \mathrm{~mm}$ diameter, $50 \mathrm{~mm}$ height and $1.5 \mathrm{~mm}$ wall-thickness. The platinum crucible was surrounded by a magnesia crucible as a support. An inverted magnesia crucible with a suitable viewing slot and a hole at the top to allow the pull rod to pass through was used as an after-heater.

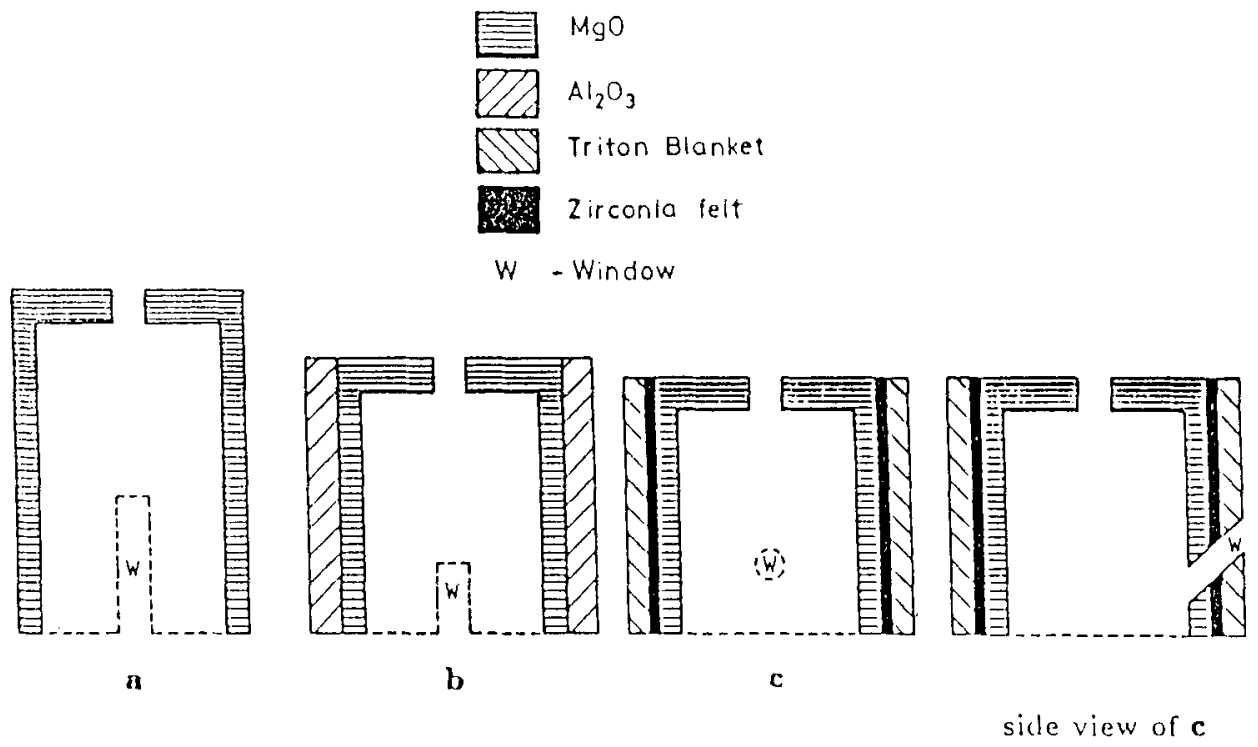

Figure 1. Systematic improvements in after-heater configurations. 
The entire assembly was surrounded by a ' $\mathrm{Y}$ '-type quartz tube inside which an $\mathrm{O}_{2}+\mathrm{Ar}$ atmosphere was maintained. The charge was melted by an RF heating system.

One of our important objectives here was to see whether the diameter of the crystal boule could be increased. As was mentioned earlier, the puller used was designed for growing $25 \mathrm{~mm}$ diameter crystals. The systematic effort on the improvement of the after-heater configuration enabled us to grow routinely $32 \mathrm{~mm}$ diameter crystals. Increase of the diameter from $25 \mathrm{~mm}$ to $32 \mathrm{~mm}$ corresponds to $45 \%$ increase in the yield by weight and an achievement of crystal to crucible diameter ratio of $64 \%$. The various stages of improvement in the after-heater configuration which led to this achievement are schematically shown in figure 1 . The improvement here is essentially in terms of reducing the heat loss and achieving less sharper temperature gradient. The configuration shown in figure 1c has considerably less heat loss through the window and by radiation thereby improving the thermal conditions.

In most cases the crystals were found to be colourless, though at times the crystals grown were with a slight yellowish tinge. The coloured crystals were annealed at about $1000^{\circ} \mathrm{C}$. in oxygen atmosphere for two days. After this the temperature was brought down to $300^{\circ} \mathrm{C}$ at a rate of $25^{\circ} \mathrm{C} / \mathrm{h}$ and then the furnace was switched off. The annealing procedure not only makes the crystal colourless, but also removes thermal stress, if any, present in the crystal. Figure 2 shows two $c$ cut wafers of $\mathrm{LiNbO}_{3}$ which clearly show the improvement in terms of diameter.

To study the domain structure, polished $c$ cut crystals were etched in $\mathrm{HF}$ and $\mathrm{HNO}_{3}$ in $1: 2$ ratio at about $100^{\circ} \mathrm{C}$ for 30 to $45 \mathrm{~min}$ in a temperature-controlled bath. The difference in the etching rate between the positive and negative domains was observed with a polarizing microscope. Figure 3 a shows a typical domain pattern in unpoled $\mathrm{LiNbO}_{3}$. In order to monodomainize the crystal, blocks cut perpendicular to $c$-axis were poled at high temperature, for which purpose platinum paste 31333 supplied by Eltech Corporation, India, was used. The crystal coated with the platinum paste was kept in between two platinum plates, from which platinum wires were taken out. The whole assembly was kept in the uniform temperature region of a Stanton Redcraft tubular furnace controlled by a temperature programmer/controller.

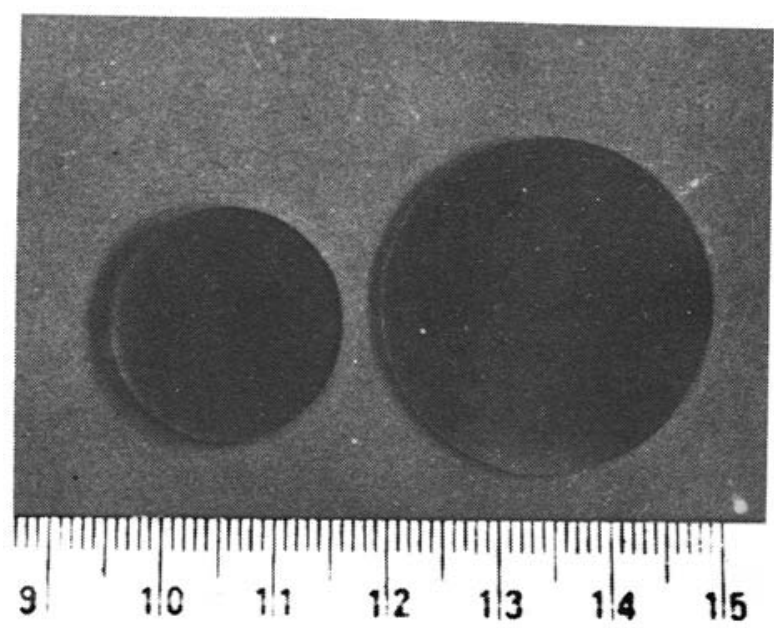

Figure 2. $\mathrm{LiNbO}_{3}$ wafers showing improvement in boule diameter. 

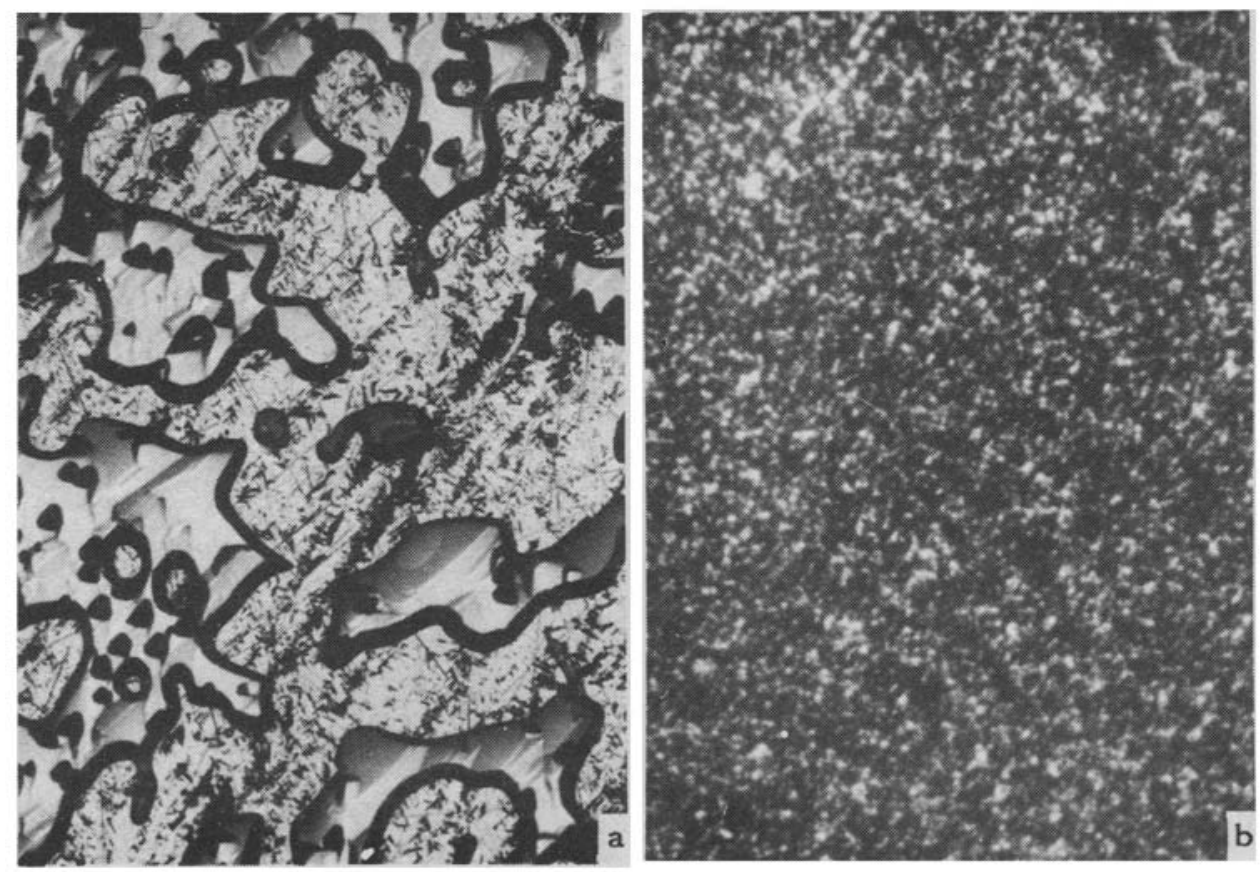

Figure 3. Domain patterns in (a) unpoled $\mathrm{LiNbO}_{3}$ and (b) poled $\mathrm{LiNbO}_{3}$ crystal (showing positive domain) $(\times 75)$.

The crystal was heated to $1200^{\circ} \mathrm{C}$ at a rate of $5^{\circ} \mathrm{C} / \mathrm{min}$. A $2 \mathrm{~mA} / \mathrm{cm}^{2} \mathrm{dc}$ current was passed through the crystal using a Keithly constant-current source. It was cooled slowly at a rate of $20^{\circ} \mathrm{C} / \mathrm{h}$ up to $1000^{\circ} \mathrm{C}$ with polarizing current and then at a rate of $100^{\circ} \mathrm{C} / \mathrm{h}$ to room temperature. The crystal was removed from the furnace at room temperature. After lightly polishing the crystal it was etched again in $\mathrm{HF}$ and $\mathrm{HNO}_{3}$ in $1: 2$ ratio. Figure $3 b$ shows the domain structure on the positive face of the crystal. As can be seen from the figure, the resulting crystal boule is of single domain nature.

\subsection{Potassium titanyl phosphate}

Potassium titanyl phosphate $\left(\mathrm{KTiOPO}_{4}\right)$ commonly known as $\mathrm{KTP}$, is a well-known nonlinear optical material frequently used for frequency doubling of Nd-doped lasers (Zumsteg et al 1976). It is also an excellent electrooptic and waveguide material, making it an ideal candidate in integrated optical applications (Bierlin and Arweiler 1986).

In our laboratory, KTP crystals are grown from potassium phosphate $\left(\mathrm{K}_{6} \mathrm{P}_{4} \mathrm{O}_{13}\right)$ flux by self-nucleation employing slow cooling. The ingredients were $\mathrm{KH}_{2} \mathrm{PO}_{4}$ (AR grade), $\mathrm{TiO}_{2}$ (GR grade) and $\mathrm{K}_{2} \mathrm{O}_{4}$ (AR grade). $\mathrm{KTiOPO}_{4}$ and $\mathrm{K}_{6} \mathrm{P}_{4} \mathrm{O}_{13}$ are obtained by the in situ reaction as follows:

$$
\begin{array}{r}
\mathrm{KH}_{2} \mathrm{PO}_{4}+\mathrm{TiO}_{2} \rightarrow \mathrm{KTiOPO}_{4}+\mathrm{H}_{2} \mathrm{O}, \\
2 \mathrm{KH}_{2} \mathrm{PO}_{4}+2 \mathrm{~K}_{2} \mathrm{HPO}_{4} \rightarrow \mathrm{K}_{6} \mathrm{P}_{4} \mathrm{O}_{13}+3 \mathrm{H}_{2} \mathrm{O} .
\end{array}
$$




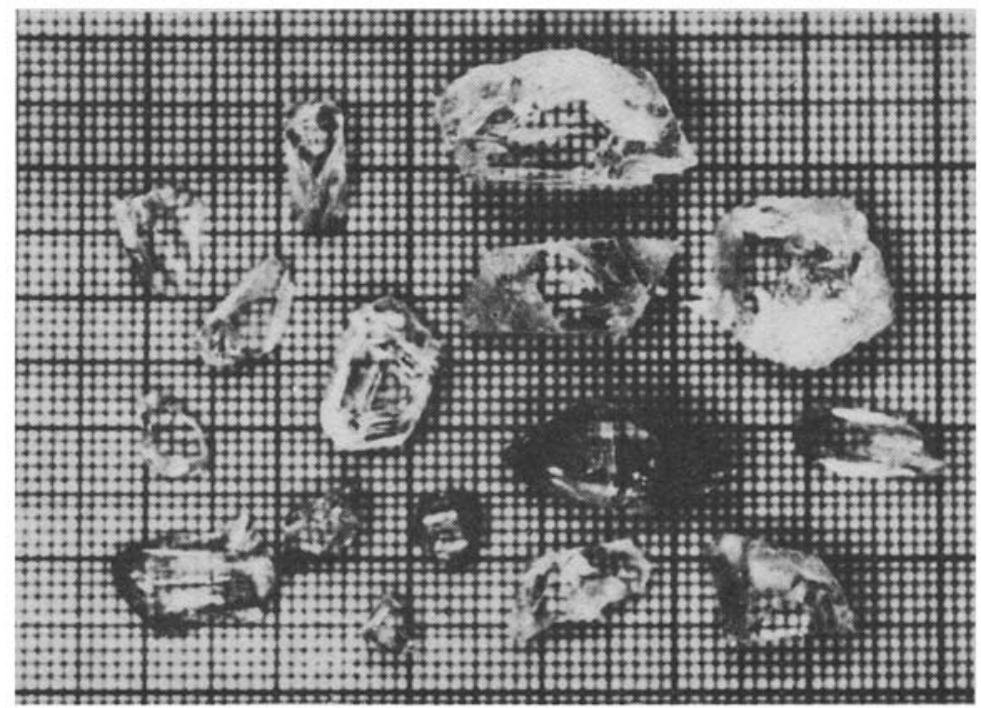

Figure 4. Typical KTP crystals grown from flux.

The ingredients were taken in a platinum crucible and kept at $1050^{\circ} \mathrm{C}$ for homogenization. After two days of homogenization the temperature was brought down to saturation temperature (i.e. $975^{\circ} \mathrm{C}$ ) and slow cooling was started. Different cooling rates and different termination temperatures (temperature at which the furnace power was switched off) were used. After the completion of programmed cooling, the furnace was allowed to reach room temperature by natural cooling after which the crucible was taken out and the flux was dissolved in hot water to harvest the crystals. Figure 4 shows typical KTP crystals grown in the laboratory. The crystals selected for microtopographical observation were cleaned thoroughly with hot water using a fine brush. The crystal habit faces were viewed under a Leitz Orthoplan polarizing microscope in reflection mode.

Interesting dendritic structures were obtained on the habit faces which mainly depend on the cooling rates. For example the habit faces of crystals grown under very fast cooling rates (say $1-2^{\circ} \mathrm{C} / \mathrm{h}$ ) exhibited highly coarse dendritic structures. As cooling rate is lowered the dendritic structure becomes finer in nature and dendritic density also decreases. Under very low cooling rates (say $2^{\circ} \mathrm{C} /$ day) smooth stepped surfaces without any dendrites could be obtained. These dendritic structures are formed because of the rapid increase in supersaturation during the final stages of growth, i.e. when the flux is approaching the solidification temperature. The underlying step pattern on the (100) habit faces is a clear manifestation of two-dimensional layer growth mechanism operating in the growth of these crystals. The details of these studies have already been published (Dhanaraj and Bhat 1990).

Recently we have made considerable progress in growing these crystals by topseeded solution growth technique, for which purpose the required facility has been indigenously fabricated. Currently efforts are on in optimizing the growth conditions (Satyanarayan and Bhat 1993). 


\subsection{3-Methoxy-4-hydroxybenzaldehyde}

3-Methoxy-4-hydroxybenzaldehyde (MHBA), is an efficient molecular nonlinear optical material. This has relatively weak donor and acceptor $(-\mathrm{CHO}$ and $-\mathrm{OH})$ at para positions in a benzene ring and $-\mathrm{OCH}_{3}$ group attached at the meta position, ensuring an acentric crystal structure. Its powder SHG efficiency is as high as 30 times that of urea and it has transparency down to $362 \mathrm{~nm}$ (Yakovlov and Poezzhalov 1991; Tao et al 1992; Zhang et al 1993). A combination of these properties makes MHBA an excellent material for investigation as a potential frequency doubler for GaAs lasers, useful in high-storage-density optical memories.

3.3a Growth from solution: Earlier workers have grown crystals of MHBA from different solvents (Singh et al 1991; Tao et al 1992; Zhang et al 1992). Since we found out that most of the attempted solvents (water, methanol, chloroform, acetic acid) were not very suitable for crystal growth of MHBA, we tried mixtures of these solvents in different proportions. Crystals large enough for characterization were obtained from either a mixture of acetic acid and water or chloroform and acetone and are shown in figure 5 . Though the mixture of acetic acid and water gave larger crystals, under the prolonged growth durations required for achieving this the solution turned deep yellowish in colour. We found that for better optical-quality crystals, a mixture of chloroform and acetone is more suitable. A summary highlighting the extremes of the results obtained in some solvent mixtures is presented in table 4. MHBA grows as rods and needles from many of the solvents and solvent mixtures (not listed here). This is due to the fact that the molecules align easily head-to-tail forming hydrogen bonds with the solvent molecules.

$3.3 b$ Growth from melt: It has been reported that the melting point of MHBA is $82^{\circ} \mathrm{C}$ and the compound does not undergo any phase transition till that temperature (Zhang et al 1992). Differential scanning calorimetry carried out by us indicated that

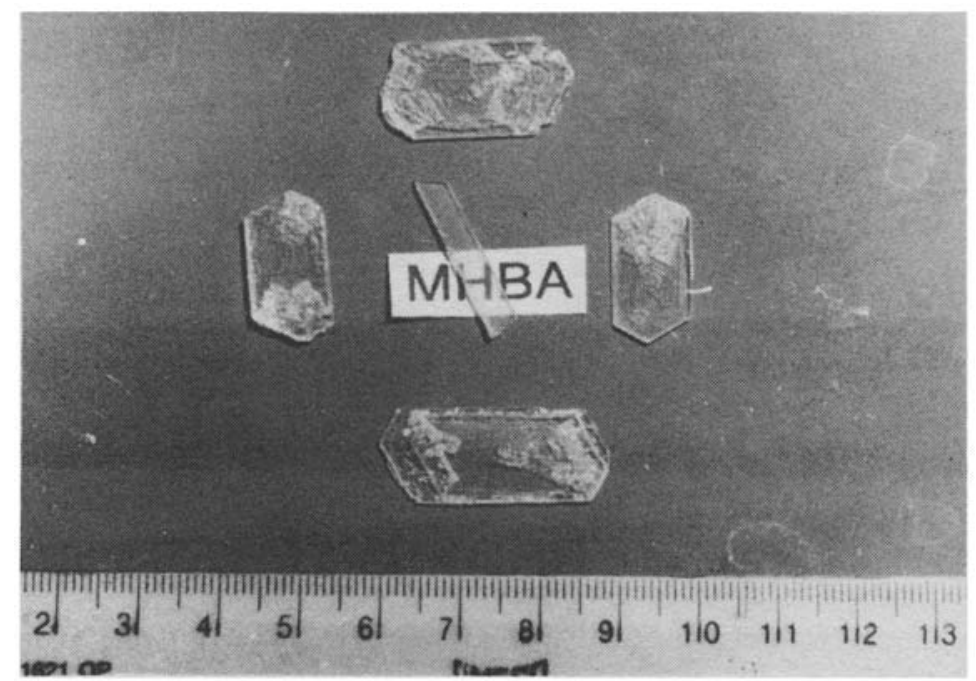

Figure 5. MHBA crystal grown from chloroform-acetone mixture. 
Table 4. Influence of solvent mixtures on the growth habit of MHBA.

\begin{tabular}{lcll}
\hline Solvent mixtures & $\begin{array}{c}\text { Solubility } \\
(\mathrm{g} / 100 \mathrm{ml})\end{array}$ & Habit & $\begin{array}{l}\text { Optical } \\
\text { quality }\end{array}$ \\
\hline Acetic acid + water $(2: 1)$ & 40.9 & Plates & Good \\
Acetic acid + water $(1: 1)$ & 28.4 & Prisms & Good \\
Acetic acid + water $(1: 2)$ & 14.59 & Plates & Good \\
Chloroform + acetone $(1: 1)$ & $73 \cdot 72$ & Plates & Very good \\
Chloroform + acetic acid $(1: 1)$ & $32 \cdot 02$ & Prisms & Good \\
\hline
\end{tabular}

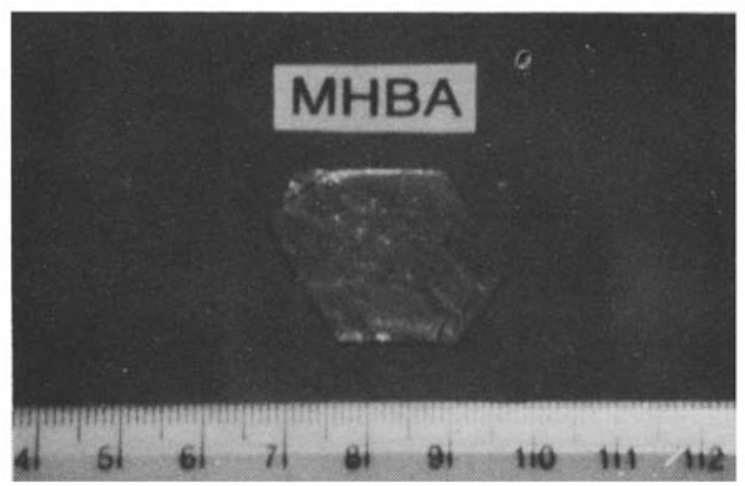

Figure 6. An MHBA crystal grown from undercooled melt.

the compound melts at $82^{\circ} \mathrm{C}$, solidifies below $50^{\circ} \mathrm{C}$, and does not decompose till $90^{\circ} \mathrm{C}$. Hence attempts were made to grow crystals from the undercooled melt (Venkataramanan et al 1994a). The material was taken in a $250 \mathrm{ml}$ flask and melted at $82.5^{\circ} \mathrm{C}$. The charge was then slowly cooled down to $81^{\circ} \mathrm{C}$ to supercool it by $1.5^{\circ} \mathrm{C}$. A seed crystal grown by spontaneous nucleation was carefully lowered into the melt and made to grow by release of latent heat of crystallization. Crystals of size $30 \times$ $20 \times 2 \mathrm{~mm}^{3}$ were grown in $6 \mathrm{~h}$ (figure 6). The grown crystals were polymorphic in habit and had good transparency. Further, unlike solution-grown crystals, these crystals did not suffer from inclusions and their preferential incorporation into certain regions. From this point of view, the melt growth is more suitable for growing MHBA crystals.

\section{$3.4 L A P$ and $d L A P$}

L-Arginine phosphate monohydrate (generally known as LAP), with chemical formula

$$
\left[\mathrm{H}_{2} \mathrm{~N}\right]_{2}^{+} \mathrm{CNH}\left(\mathrm{CH}_{2}\right)_{3} \mathrm{CH}\left[\mathrm{NH}_{3}\right]^{+} \mathrm{COO}^{-} \mathrm{H}_{2} \mathrm{PO}_{4}^{-} \cdot \mathrm{H}_{2} \mathrm{O} \text {, }
$$

is one of the new type I semiorganic nonlinear optical materials. Compared to KDP, LAP is nearly three times more nonlinear, is more angularly sensitive, has a damage threshold 2 to 3 times higher, and is less deliquescent (Eimerl et al 1989; Sasaki et al 


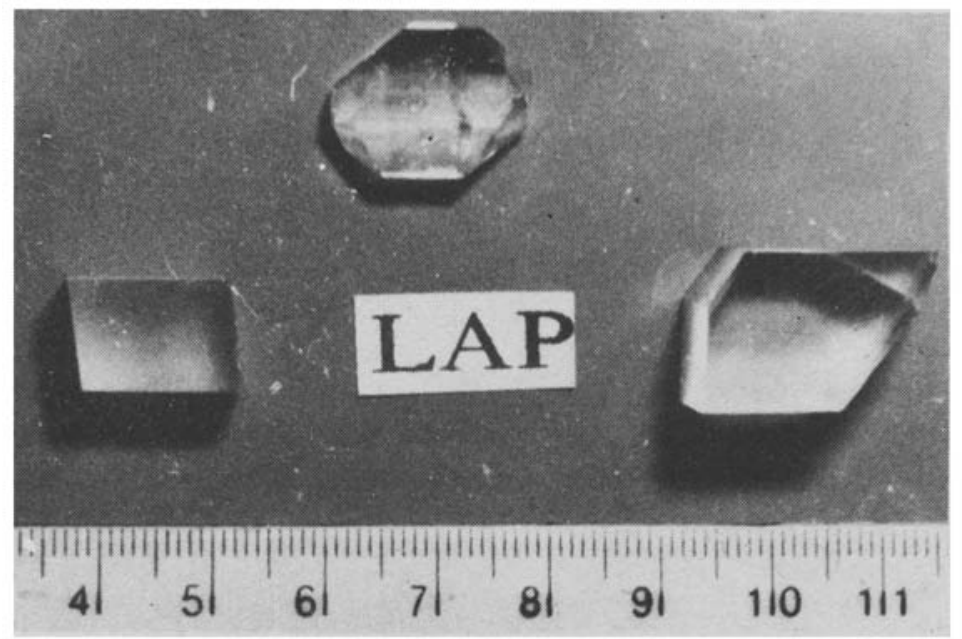

Figure 7. Typical LAP crystals grown.

1989; Yokatani et al 1989). It crystallizes in monoclinic structure with space group $\mathrm{P} 2{ }_{1}$ and is optically biaxial (Aoki et al 1971). LAP has an absorption band around the Nd:YAG laser fundamental which can be red-shifted by deuterating it. Hence dLAP has an added advantage for frequency conversion applications of $\mathrm{Nd}$ lasers. LAP crystals are grown in our laboratory from aqueous solutions by slow cooling as well as by slow evaporation. The problems associated with growth of LAP, like microbial growth and colouration of the solution, have been investigated and the details have been published elsewhere (Dhanaraj et al 1991). Large LAP crystals are grown by slow cooling from $45^{\circ} \mathrm{C}$ to $30^{\circ} \mathrm{C}$ at the rate of $0.2{ }^{\circ} \mathrm{C}$ to $0.5^{\circ} \mathrm{C}$ per day (figure 7). The ideal morphology of LAP and its variations under different growth conditions ( $\mathrm{pH}$ and colouration of the solution) have already been reported by us (Dhanaraj et al 1991).

Deuterated LAP is synthesized in a glove box in $\mathrm{N}_{2}$ atmosphere using $\mathrm{D}_{2} \mathrm{O}, \mathrm{P}_{2} \mathrm{O}_{5}$ and L-arginine. Seed crystals of dLAP are prepared by spontaneous nucleation in a sealed flask by slow cooling. Growth of dLAP is carried out in a closed flask with a $n$-hexane layer on the surface of the solution. Slow cooling is carried out from $35^{\circ} \mathrm{C}$ to $20^{\circ} \mathrm{C}$ at a rate of $0.5^{\circ} \mathrm{C}$ a day. Crystals up to $13 \times 10 \times 8 \mathrm{~mm}^{3}$ could be grown in $100 \mathrm{ml}$ solution. Figure 8 shows a photograph of typical dLAP crystals. The morphology of these crystals is quite similar to that of LAP (Venkataramanan et al 1994b).

The prominent microbial species identified in LAP solutions are of Aspergillus family. Most of the microbes that grow in LAP were found to be aerobic. A layer of immiscible liquid over the growth solution can isolate the solution from the atmosphere, thereby preventing microbial growth. We covered sterilized LAP solution with a thick layer of $n$-hexane and were able to alleviate the problem (Dhanaraj et al 1991).

A recent experiment on KDP growth (Wang et al 1992) has revealed that addition of droplets of mercury to the growth solution reduces microbial growth. We also found that addition of $\mathrm{Hg}$ in the LAP solution delays the appearance of microbial colonies, if not completely eliminate it. However, from our experience, the technique 


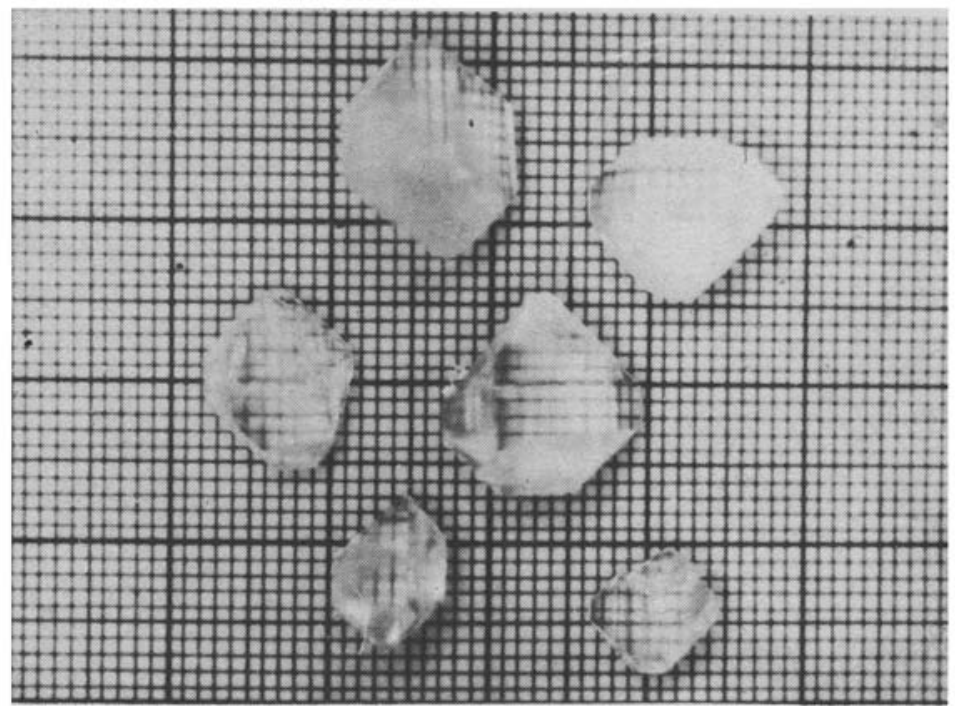

Figure 8. Typical dLAP crystals grown.

of covering the sterilized solution with a thick layer of immiscible liquid seems to be the most effective method to prevent microbial growth for extended periods. The problem of microbial growth and the influence of $\mathrm{pH}, \mathrm{Hg}$ and a layer of $n$-hexane were common for both LAP and dLAP.

\subsection{Zinc tris(thiourea) sulphate}

Zinc tris(thiourea) sulphate (ZTS) is a recently developed type II semiorganic nonlinear crystal (Marcy et al 1992). It is a good example of NLO material in which large nonlinearity of a $\pi$ conjugate organic material is combined with favourable crystal growth behaviour and mechanical properties. As a first step ZTS was synthesized from $\mathrm{ZnSO}_{4}$ and thiourea following the reaction

$$
\mathrm{ZnSO}_{4}+3 \mathrm{CS}\left(\mathrm{NH}_{2}\right)_{2} \rightarrow \mathrm{Zn}\left[\mathrm{CS}\left(\mathrm{NH}_{2}\right)_{2}\right]_{3} \mathrm{SO}_{4} \text {. }
$$

The mixture had to be stirred vigorously to avoid precipitation of other phases. The resultant precipitate of ZTS was dried and weighed to measure the yield. The product was further purified by repeated recrystallization from hot water. Thiourea has the coordinating capacity to form a variety of zinc-thiourea complexes. To ensure purity of yield, a powder $\mathrm{X}$-ray diffractogram was taken after every synthesis and analysed for mixed phases.

Since no solubility data were available in the literature for ZTS, efforts were made to measure the solubility in water. Solubility was measured from $30^{\circ} \mathrm{C}$ to $80^{\circ} \mathrm{C}$ in steps of $5^{\circ} \mathrm{C}$ or less. The resultant data could be fitted to a curve following the equation

$$
S=a t^{2}+b t+c
$$

where $S$ is the solubility expressed in $\mathrm{g} / 100 \mathrm{ml}$ and $t$ the temperature in ${ }^{\circ} \mathrm{C}$. The 
constants evaluated were $a=9.979 \times 10^{-4}, b=-0.0055$ and $c=4.6879$. Figure 9 is the solubility curve for ZTS. It can be seen from the curve that though there is a positive slope, the variation of solubility with temperature is quite low. This proved to be a serious handicap in growing large crystals by slow cooling and hence solvent evaporation was adopted as the technique to grow the crystals. Subsequently, single crystals of ZTS were grown from aqueous solution by evaporation at room temperature. Crystals up to $25 \times 12 \times 3 \mathrm{~mm}^{3}$ could be grown without seeding in about two weeks time. The crystals grown by spontaneous nucleation were optically transparent and free from visible inclusions. They were generally platy with the prominent face containing [100] plane. Good optical-quality crystals as large as $24 \times 18 \times 16 \mathrm{~mm}^{3}$ were grown subsequently by seeding the saturated solution and by evaporation of solvent (figure 10). The crystals were nonhygroscopic and optically transparent. Further work is in progress.

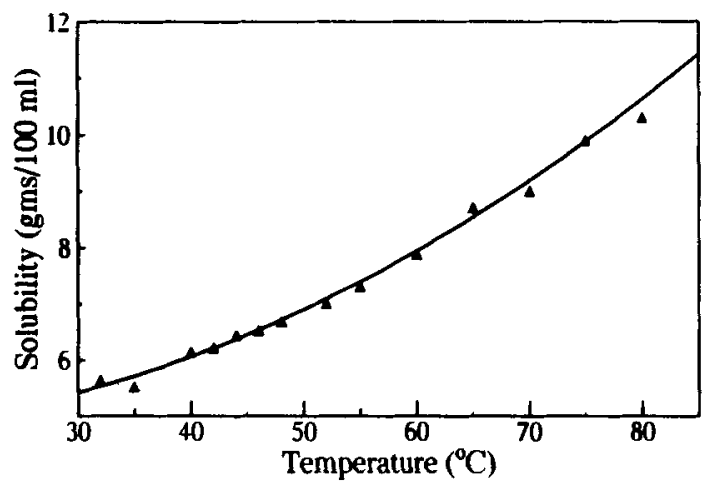

Figure 9. Solubility curve for ZTS with water as solvent.

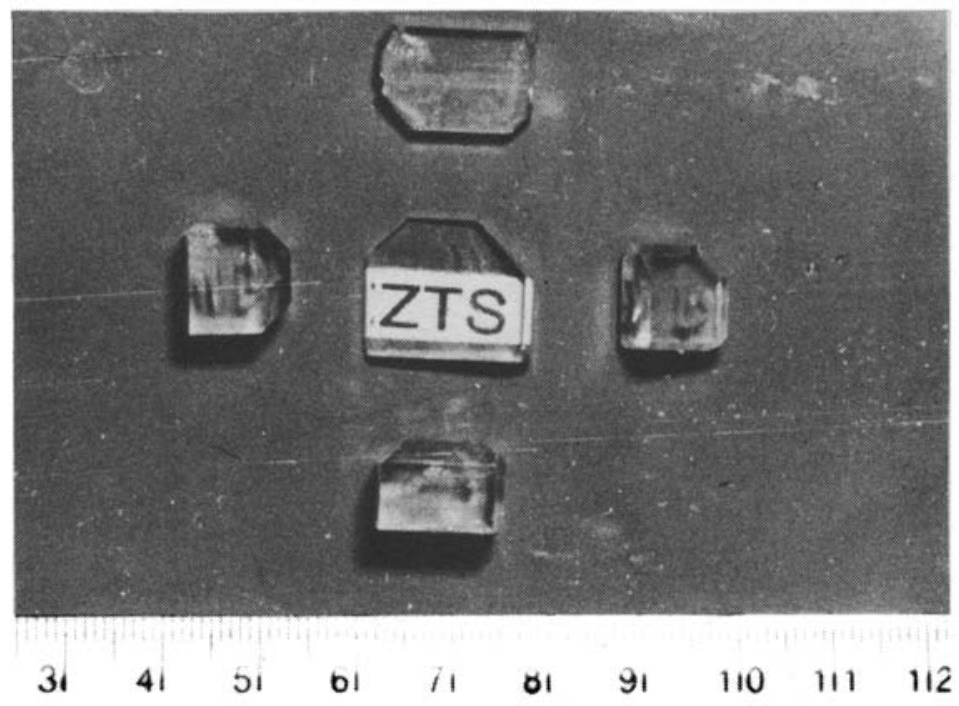

Figure 10. Optical-quality ZTS crystals. 


\section{Conclusions}

In this review we have briefly discussed nonlinear optical crystals from the materials points of view. Initially an elementary introduction to nonlinear optical phenomena with emphasis on second harmonic generation was given. The material parameters to be optimized for maximizing SHG efficiency were then highlighted. The present status of three classes of NLO materials, viz. inorganics, organics and semiorganics, has been summarized. A brief account of crystal growth experiments carried out in the author's laboratory on some typical crystals belonging to each of the above class is given.

\section{Acknowledgements}

The crystal growth aspects presented in this article were carried out by three of my PhD students, viz. G Dhanaraj, V Venkataramanan and M N Satyanarayan. Their enthusiasm and untiring efforts are very much appreciated. The work has been financially supported by a number of funding organizations like DST, UGC, DRDO, ISRO, DAE and British Council over the years. I am very much grateful to these organizations. The technical help given by Mr S Maheswaran in the preparation of this article is gratefully acknowledged.

\section{References}

Aoki K, Nagano K and Iitaka Y 1971 Acta Crystallogr. B27 11

Bergman J G Jr, Boyd G D, Ashkin A and Kurtz S K 1969 J. Appl. Phys. 402860

Bierlin J D and Arweiler C B 1986 Appl. Phys. Lett. 49917

Chemla D S and Zyss J 1987 Nonlinear optical properties of organic molecules and crystals (New York: Academic Press) vols. I and II

Dhanaraj G and Bhat H L 1990 Mater. Lett. 10283

Dhanaraj G, Shripathi T and Bhat H L 1991 J. Cryst. Growth 113456

Eimerl D, Velsko S, Davis L, Wang F, Loiacono G and Kennedy G 1989 IEEE J. Quantum Electron. QE25 179

Franken P A, Hill A E, Peters C W and Weinreich G 1961 Phys. Rev. Lett. 7118

Lin J T 1988 OE-LASE 1988, Los Angeles, CA, USA

Marcy H O, Warren L F, Webb M S, Ebbers C A, Velsko S P, Kennedy G C and Catella G C 1992 Appl. Opt. 315051

Newman P R, Warren L F, Cunningham P, Chang T Y, Cooper D E, Burdge G L, Polak-Dingels P and Lowe-Ma C K 1990 Mater. Res. Soc. Symp. Proc. 173557

Prokhorov A M and Kuzminov Yu S 1990 Physics and chemistry of lithium niobate (Bristol: Adam Hilger)

INSPEC 1989 Properties of lithium niobate EMIS Data Reviews Series No. 5 (London and New York: The Institution of Electrical Engineers)

Sasaki T, Yokatani A, Fujioka K, Yamanaka T and Nakai S 1989 Technol. Rep. Osaka Univ. 3925

Satyanarayan M N and Bhat H L 1993 Fifth National Seminar on Crystal Growth, Madras, India

Singh N B, Henningsen T, Metz E P A, Hamacher R, Cumberledge E, Hopkins R $H$ and Mazelsky $R$ 1991 Mater. Lett. 12270

Tao X T, Yuan D R, Zhang N, Jiang M H and Shao Z S 1992 Appl: Phys. Lett. 601415

Venkataramanan V, Uchil S, Subramanian C K and Bhat H L 1994a Conf. on Emerging Optoelectronic Technologies (ed.) A Selvarajan et al (Delhi: Tata Mcgraw-Hill) pp. 71-74

Venkataramanan V, Dhanaraj G and Bhat H L 1994b J. Cryst. Growth 140336

Wang J S, Zhang M N, Bennema P, Liu Y S, Zhu R, Ye G F, Bian J and Van Enckevort W J P 1992 J. Phys. D: Appl. Phys. 251616 
Yakovlov Yu O and Poezzhalov 1991 Sov. J. Quantum Electron. 21483

Yariv A 1985 in Optical electronics (New York: Holt Rinehart)

Yokatani A, Sasaki T, Yoshida K and Nakai S 1989 Appl. Phys. Lett. 552692

Zhang N, Yuan D R, Tao X T, Shao Z S, Dou S X, Jiang M H and Xu D 1992 J. Cryst. Growth 123255

Zhang N, Yuan D R, Tao X T, Xu D, Shao Z S, Jiang M H and Liu M G 1993 Opt. Commun. 99243

Zumsteg F C, Bierlin J D and Gier T E 1976 J. Appl. Phys. 474980 